\title{
Melanin Pigmentation and Inflammation in Human Gingiva*
}

\author{
A. Patsakas, $\nmid$ N. Demetriou, $\ddagger$ and A. Angelopoulos $\S$
}

\begin{abstract}
ThE STUDY WAS carried out to determine the distribution of melanin granules in different anatomical areas of the gingiva and to relate the density of melanin granules to the degree of gingival inflammation. Specimens including free and part of the attached gingiva were secured from the vestibular surfaces of the six maxillary or mandibular teeth of 21 Caucasian subjects during periodontal surgery. Serial histologic sections 5 to $6 \mu$ thick were prepared and stained with Hematoxylin and Eosin or Masson-Fontana. Evaluation of the $\mathrm{H} \& \mathrm{E}$ stained sections disclosed that the number of melanophores and melanin granules in the epithelium and the inflammatory cells of the subepithelial connective tissue gradually decreased from the free gingival groove area to the free gingival crest and from the free gingival groove to the mucogingival junction. The density of melanophores in the vestibular epithelium showed a significant positive correlation $(r=0.38, P<0.00003)$ with the severity of inflammation (numbers of inflammatory cells) in the attached gingiva but not in the free gingiva $(r=-0.033$, $P<0.2643$ ). There was a positive significant correlation between the density of melanin granules of the vestibular epithelium and that of the adjacent connective tissue in both the free $(r=0.57, P<0.0003)$ and atached gingiva $(r=0.46, P<0.0003)$.
\end{abstract}

Studies on melanin pigmentation of the gingiva (and of the oral mucosa) have concentrated mainly on determining by epidemiologic methods the incidence of gingival pigmentation in different population groups and races $^{1-6}$ and on making logical and quantitative observations of melanocytes and Langerhans' cells by microand ultramicroscopy using histochemical techniques (DOPA). ${ }^{7-15}$

The purposes of this investigation were to study: (1) the distribution of melanin-containing cells (melanophores) and melanin granule density in different areas of the vestibular surface of the free and attached gingiva; (2) to relate these findings to the degree of inflammation of the subepithelial connective tissue; and (3) to determine the relationship between the density of the melanin granules in the epithelium and the adjacent connective tissue. For the purposes of this study, "melanophores" are considered to be keratinocytes of the epithelium or fibroblasts and macrophages of the connective tissue which contain phagocytosed melanin granules.

\section{MATERIALS AND METHODS}

Twenty-one Caucasians, 15 males and 6 females, 21

\footnotetext{
* Part of this paper was presented at the 16th Annual Meeting of the Continental European Division (CED) of the I.A.D.R. in Athens, September 14-16, 1979.

$\dagger$ Instructor, Department of Oral Pathology.

$\ddagger$ Associate Professor in the Oral Pathology Department. Presently Visiting Associate Professor, Department of Periodontics, the University of Michigan School of Dentistry, Ann Arbor, MI 48109.

$\S$ Professor and Chairman, Department of Oral Pathology, Dental School, University of Athens, Athens, Greece.
}

to 52 years old with normal melanin pigmentation and differing degrees of gingival inflammation, ${ }^{16}$ were used in this study. Gingival tissue specimens including free and part of the attached gingiva were taken from the vestibular gingiva of the anterior six maxillary or mandibular teeth during periodontal surgery. Biopsy specimens were fixed in freshly prepared $10 \%$ aqueous solution of formalin for 48 hours. Serial histologic sections, 5 to $6 \mu$ in width, were prepared and stained with Hematoxylin and Eosin (H \& E) and Masson-Fontana (Figs. 1 and 2).

The density and distribution of the melanophores and melanin granules, as well as the degree of inflammatory reaction, were determined microscopically using an ocular micrometer square (Fig. 3). The number of melanophores and degree of inflammatory reaction were determined by placing the micrometer square over the epithelial ridges (rete pegs) and by moving the aperture to the adjacent connective tissue (H \& E stain). Starting from the microscopically determined free gingival groove area and moving the micrometer square along the epitheliumconnective tissue area, eight successive microsquares (magnification $\times 400$ ) were examined along the free gingiva and another eight along the attached gingiva in both the epithelium and the adjacent connective tissue. In this way, almost the whole length of the free and attached gingiva of the tissue specimen was included in the microscopic examination.

The density and distribution of melanophores of the basal and suprabasal cell layers of the epithelium were determined by counting the melanophores in the epithelium of each microscopic square examined. The sum of 


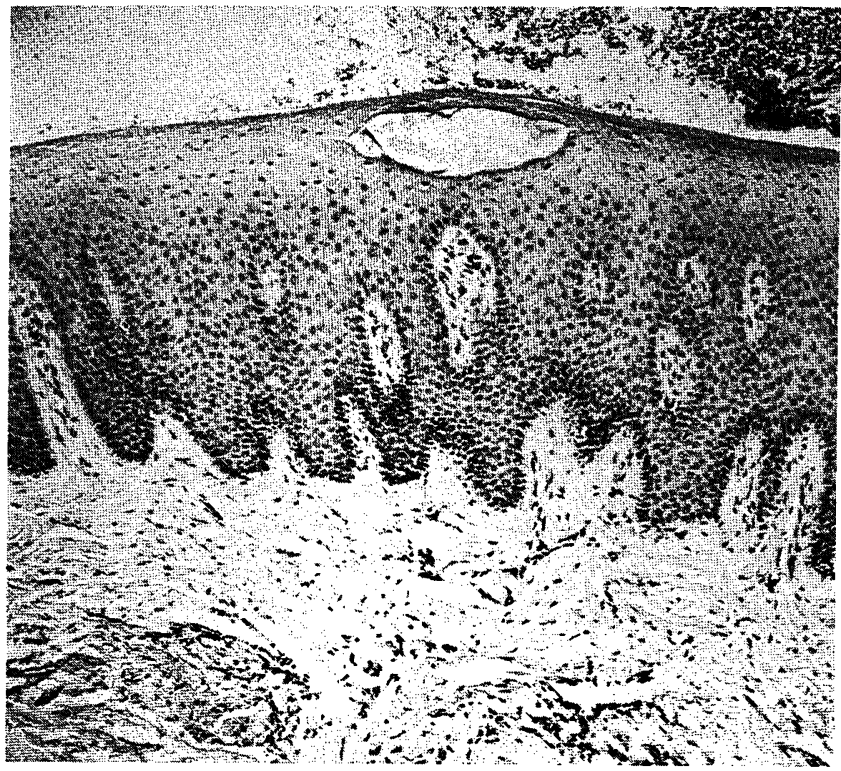

Figure 1. Photomicrograph showing the density and distribution of melanophores in the basal cell layer of the epithelium from an individual with normal gingival pigmentation. Histological specimen stained with hematoxylin and eosin.

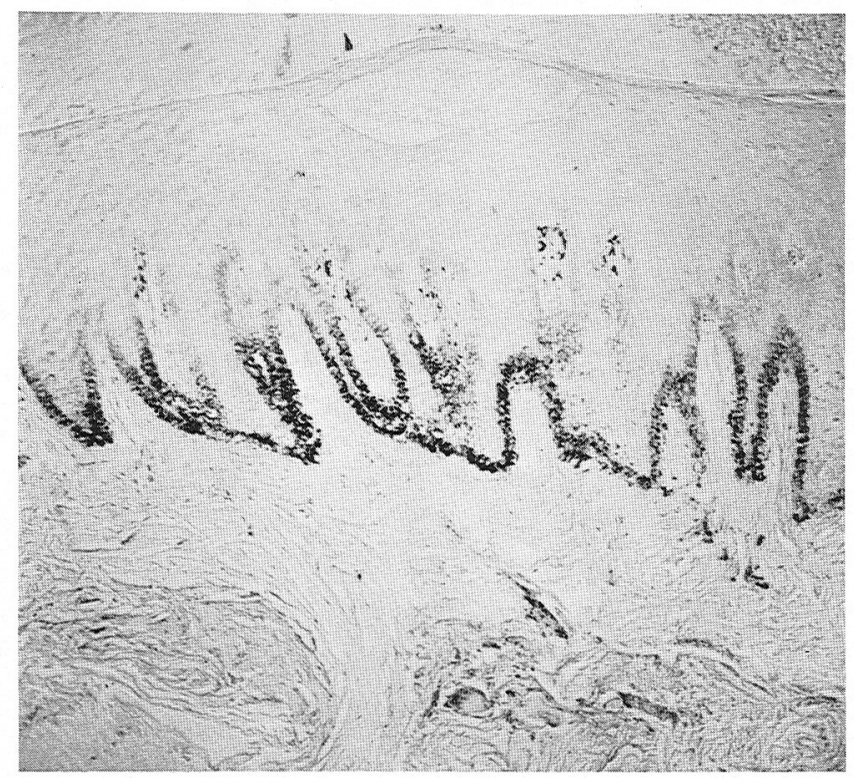

Figure 2. Photomicrograph from a serial histological section adjacent to Figure 1 but stained with Masson-Fontana. Note the increased density of melanin granules revealed by Masson-Fontana as compared with the hematoxylin \& eosin stained specimen.

the values of all microsquares examined in each of the 21 cases was computed and recorded diagrammatically (Fig. 4).

The degree of inflammation of the adjacent connective tissue area was determined by counting the inflammatory cells in each micrometer square examined. The sum of the values for all microsquares examined in each of the 21 cases was computed and recorded in the same diagram (Fig. 4).

In the Masson-Fontana stained specimens, no cell outlines containing melanin granules could be distin- guished, and thus the intensity of the pigmentation in the epithelium (mostly in the epithelial ridges) in the adjacent connective tissue was determined by measuring the density of the melanin granules in each microsquare on the basis of the following arbitrary scale: $0=$ absence of melanin granules, $1=$ rare and scattered melanin granules, 2 = dense but not aggregated melanin granules, $3=$ dense and aggregated melanin granules.

The microscopic technique used for the above-mentioned measurements and the method of computing values for the density of the melanin granules in the epithelium and the connective tissue (Fig. 5) were similar to those described for the melanophores and gingival inflammation.

Correlation coefficients were computed ${ }^{17,18}$ to determine the relationship between the density of melanophores in the epithelium and the degree of inflammation in the adjacent connective tissue, as well as the relationship between the density of the melanin granules in the epithelium and the adjacent connective tissue (Tables 1 and 2).

\section{RESULTS}

The number of melanophores in the epithelium and the inflammatory cells of the subepithelial connective tissue gradually decreased, starting from the free gingival groove area toward the gingival crest in the free gingiva, and toward the mucogingival junction in the attached gingiva (Fig. 4). In addition, the total number of mela-

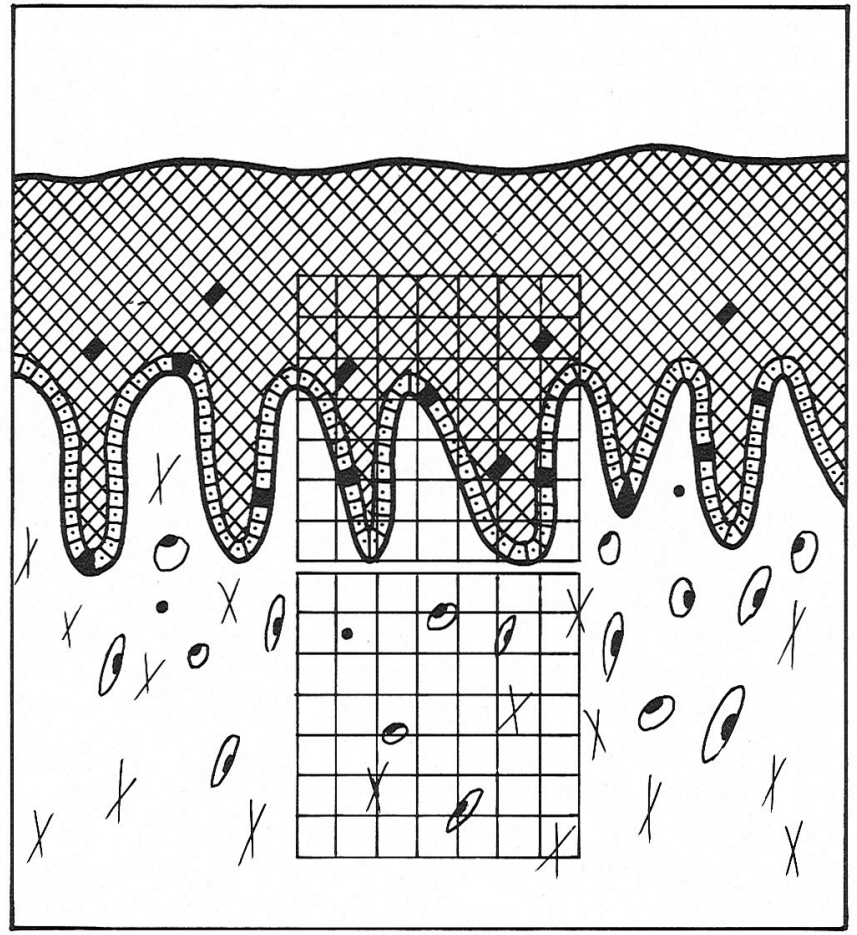

Figure 3. A diagram showing the method used to determine the density of the melanophores, the melanin granules and the degree of the inflammatory reaction. The micrometer square was placed initially at the epithelium and then moved to the adjacent connective tissue area. The same procedure was repeated all along the free and attached gingiva. 


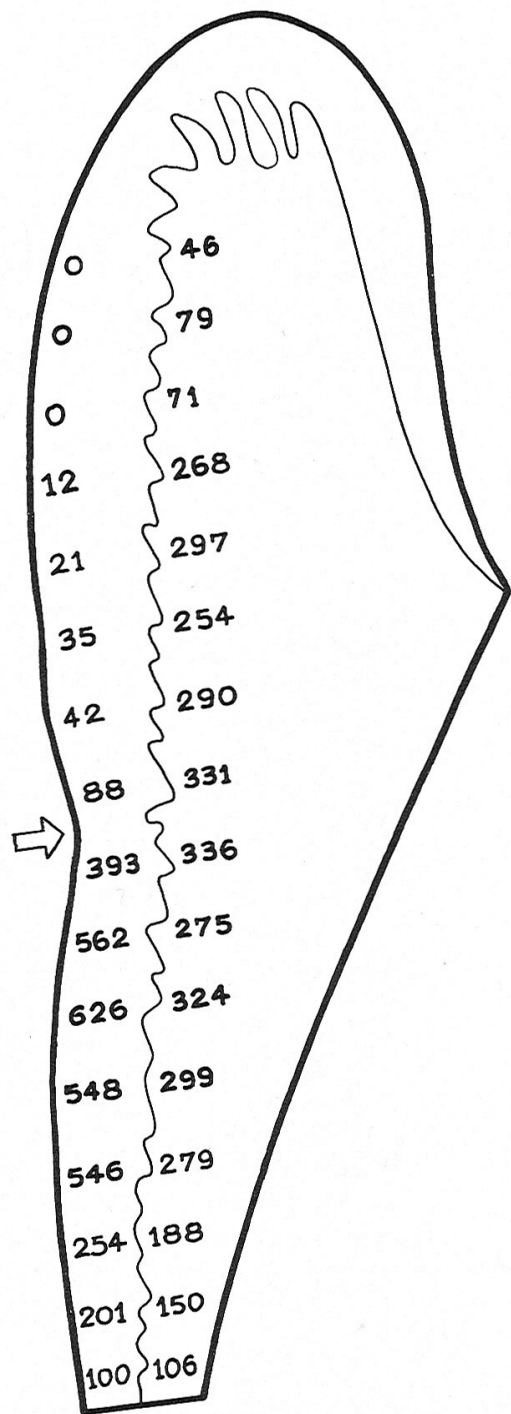

Figure 4. A composite diagram showing the distribution of melanophores in the gingival epithelium and the number of inflammatory cells of the subjacent connective tissue ( $H$ and $E$ stain). The arrow $(\rightarrow)$ denotes the free gingival groove area.

nophores in the attached gingiva (3230) was approximately 16 times greater than in the free gingiva (198), for the same number of microsquares examined in these two areas.

A similar pattern of gradual decrease from the free gingival groove toward the gingival crest and to the mucogingival line was observed for the melanin granules of the epithelium and of the adjacent connective tissue area in both the free and attached gingiva (Fig. 5).

Furthermore, the density of the melanophores (number of melanophores per unit area) of the vestibular epithelium was positively and significantly correlated with the severity of inflammation (numbers of inflammatory cells) in the attached gingiva $(r=0.38, P<$ $0.00003)$, but not in the free gingiva $(r=-0.033, P<$ 0.2643) (Table 1).

On the other hand, there was a positive and highly significant correlation between the density of melanin granules of the epithelium and that of the adjacent

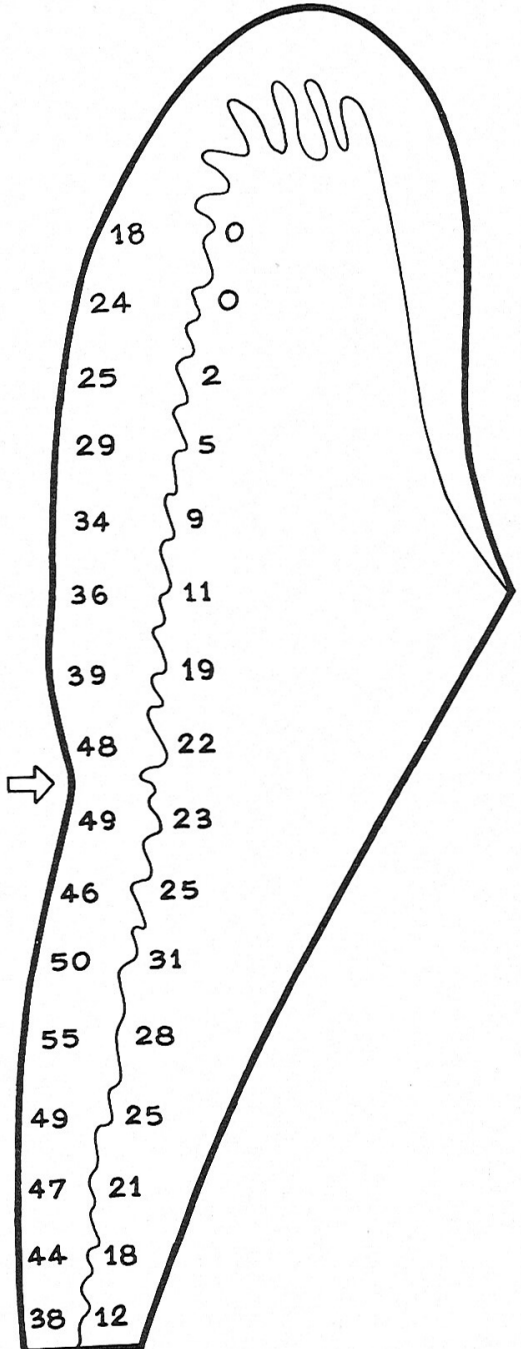

Figure 5. A composite diagram showing the density of melanin granules in the epithelium and the subjacent connective tissue (Masson-Fontana stain). The arrow $(\rightarrow)$ denotes the free gingival groove.

Table 1

Correlation Coefficients Between the Density of Melanophores and the Density of the Inflammatory Reactions in the Free and Attached Gingiva (H and E Stain)

\begin{tabular}{ccccc}
\hline Zone & $\begin{array}{c}\text { Number of } \\
\text { microscopic } \\
\text { measure- } \\
\text { ments }\end{array}$ & $r$ & $\mathrm{z}$ & Probability \\
\hline $\begin{array}{c}\text { Free gin- } \\
\text { giva }\end{array}$ & 168 & -0.033 & -0.63 & $P<0.2643$ N.S. \\
$\begin{array}{c}\text { Attached } \\
\text { gingiva }\end{array}$ & 168 & 0.38 & 7.32 & $P<0.00003$ \\
\hline
\end{tabular}

Table 2

Correlation Coefficients of the Density of Melanin Granules Between the Epithelium and the Connective Tissue in the Free and the Attached Gingiva (Masson-Fontana Stain)

\begin{tabular}{lccrc}
\hline Zone & $\begin{array}{c}\text { Number of } \\
\text { microscopic } \\
\text { measure- } \\
\text { ments }\end{array}$ & $r$ & $\mathrm{z}$ & Probability \\
\hline Free gingiva & 168 & 0.57 & 10.98 & $P<0.00003$ \\
Attached gingiva & 168 & 0.46 & 8.86 & $P<0.00003$ \\
\hline
\end{tabular}


connective tissue in both the free $(r=0.57, P<0.0003)$ and attached gingiva $(r=0.46, P<0.00003)$ (Table 2$)$.

\section{DISCUSSION}

In this study the microscopically determined melanin distribution pattern in the free and attached gingiva was compatible with the classically described clinical topography of melanin pigmentation in the gingiva. The relative scarcity of melanophores in the free as compared with the attached gingiva is the logical explanation for the absence of clinically detected pigmentation in the gingiva. However, in the Masson-Fontana stain there was no great variation in density of pigmentation between the free and attached gingiva. This contrasted with findings for the $\mathrm{H} \& \mathrm{E}$ stained specimens, and the difference may have been due: (1) to the difference in staining techniques (Masson-Fontana reveals many more granules than does $\mathrm{H} \& \mathrm{E}$ and/or (2) to the different mode of determination of melanin pigmentation (the melanophores were counted in the $\mathrm{H} \& \mathrm{E}$ method, as against the Masson-Fontana method of estimating the density of the granules in the epithelium on the basis of an arbitrary scale of $0,1,2,3$ ).

An interesting observation was that the melanophores of the epithelium increased in density as the inflammation of adjacent connective tissue in the attached gingiva increased in severity. This may have been due to the stimulating effect of inflammation on the capacity of melanocytes to produce increased amounts of melanin. ${ }^{19,}{ }^{20}$ A stimulation effect of inflammation upon the mitotic activity of the epithelial cells has been proposed by several authors. ${ }^{21,22}$ However, such a relationship between melanophores and inflammation was not found to be significant in the free gingiva ( $r=-0.033, P<0.2643$ ). This could be attributed to the scarcity of the melanophores $(0-1$ melanophores per micrometer square) in the free gingiva.

\section{CONCLUSIONS}

1. Melanophores of the gingival epithelium are mainly located in the attached rather than the free gingiva and in the basal and suprabasal cell layers.

2. The number of melanophores and the density of the melanin granules decrease gradually starting from the free gingival groove area toward the gingival crest and toward the mucogingival junction.

3. The number of melanophores of the gingival epithelium per unit area is directly correlated with the severity of inflammation (numbers of inflammatory cells) in the subjacent connective tissue of the attached gingiva.

4. The density of the melanin granules of the vestibular gingival epithelium is directly correlated with the melanin granule density of the subjacent connective tissue of both the free and attached gingiva.

\section{REFERENCES}

1. Ando, Y., Suetaka, T., and Sakuma, I.: A statistical investigation of gingival pigmentation. Dent Abstr 1: 749, 1956.

2. Steigmann, S.: The relationship between physiologic pigmentation of the skin and oral mucosa in Yemenite Jews. Oral Surg 19: 32, 1965.

3. Brown, T.: Oral pigmentation in the aborigines of Kalumburu, northest Australia. Arch Oral Biol 9: 555, 1964.

4. Dummett, $\mathrm{Cl}$., and Barens, G.: Oromucosal pigmentation: An updated literary review. $J$ Periodontol 42: 726, 1971.

5. Dummett, $\mathrm{Cl}$., and Barens, G.: Pigmentation of the oral tissues. A review of the literature. J Periodontol 38: 369, 1967.

6. Breijer, H. B. G., and Lignao, G. O. E.: Melanin pigmentation of the dental mucosa in Dutchmen. Doc Med Geogr Trop 5: 42, 1953.

7. Barker, D. S.: The dendritic cell system in human gingival epithelium. Arch Oral Biol 12: 203, 1967.

8. Schroeder, H. E.: Melanin containing organelles in cells of the human gingiva. I. Epithelial melanocytes. J Periodont Res 4: 1, 1969.

9. Schroeder, H. E.: Melanin containing organelles in cells of the human gingiva. II. Keratinocytes. J Periodont Res 4: 235, 1969.

10. Schroeder, H. E.: Malanin containing organelles in cells of the human gingiva. III. Connective tissue cells. Helv Odontol Acta 13: 46, 1969.

11. Soames, J. V.: The morphology and quantitative distribution of dopa-positive melanocytes in the gingival epithelium of Caucasians. Oral Surg 38: 254, 1974.

12. Hutchens, L. H., Sagebiel, R. W., and Clarke, M. A.: Oral epithelial dendritic cells of the Rhesus monkey. Histologic demonstration, fine structure and quantitative distribution. J Invest Dermatol 56: $325,1971$.

13. Squier, C. A.: A study of the dendritic cells in separated sheets of oral epithelium in the rat. Arch Oral Biol 14: 381, 1969.

14. Squier, C. A., and Waterhouse, J. P.: The ultrastructure of the melanocyte in human gingival epithelium. Arch Oral Biol 12: 119, 1967.

15. Cohen, L.: ATPase and DOPA oxidase activity in human gingival epithelium. Arch Oral Biol 12: 1241, 1967.

16. Patsakas, A.: A clinical and histologic study of the physiologic pigmentation of the oral mucosa. Thesis, School of Dentistry University of Athens, Athens 1979.

17. Hill, A. B.: Principles of Medical Statistics, p 180. New York, Oxford University Press, 1966.

18. Siegel, S.: Nonparametric Statistics for the Behavioral Sciences, p 220. New York. McGraw-Hill Book Co., Inc., 1956.

19. Billingham, R. E., and Silvers, W. K.: The melanocytes of the animals. $Q$ Rev Biol 35: 1, 1960.

20. Busuthil, A.: Dentritic pigmented cells within human laryngeal mucosa. Arch Otolaryngol 102: 43, 1976.

21. McHugh, W. D., and Zander, H. A.: Cell division in the periodontium of developing and erupted teeth. Dent Pract 15: 451, 1965

22. Mühlemann, H. R., and Hartl, St.: Daily variations of mitotic rate and inflammatory cell migration in the epithelium of the intermolar rat papilla. Bull Schweiz Akad Med Wiss 11: 379, 1955.

Send reprint requests to: Dr. Nikitas Demetriou, 45 Michalacopoulou St, Athens (612), Greece. 